\title{
Introduction: "Hallo TV"
}

On 13 June 1992, a strange television show premiered during the morning schedule of German public broadcaster 3sat. There were no presenters, no announcements, no explanations. In fact, no show at all. Instead, you could call a telephone number that was displayed on the TV screen. And if you were lucky and got through, you were suddenly on air and could speak to the world via TV. Up to four callers found themselves in a strange, random community, could chat with each other or give a speech to mankind. Many callers were so startled that they hung up immediately. Others managed little more than "Hallo". Some tried to make conversation with the other callers. Others made farting noises until they were thrown off the line.

The show was called Piazza virtuale. It was a unique experiment in the history of television. As a special project of documenta IX, it was broadcast for 100 days in the summer of 1992 from a container studio next to the Fridericianum, documenta's main site. Organised by artists' group Van Gogh TV, the show consisted of largely unmoderated contributions from the audience, who provided the content of the programme by phone calls, fax or computer chat. The aim of the artists was to put Bertolt Brecht's famous demand from his Radio Theorie into practice: Consumers of media content were to become producers of it. In addition to the phone-in programme Coffeehouse, there were interactive parts of the show where viewers could paint or make music together using the keyboard of their phone.

The Piazza virtuale studio in Kassel. From left: Ole Lütjens, Salvatore Vanasco, Anne-Katrin Brinkmann, Christian Wolff, in the foreground visiting members of the Chaos Computer Club

Photo: Ali Altschaffel (altschaffel.com) 
Van Gogh TV was an association of artists and hackers that emerged from the Minus Delta t performance group. The founders of the collective, the artists Mike Hentz, Karel Dudesek, Benjamin Heidersberger and Salvatore Vanasco, had worked systematically to open up the media to its audience since the creation of the group. In doing so, they anticipated forms of programming and interaction that have only become established with the help of the "social media" of the last two decades.

They gathered a team that built a completely computerised studio out of commercially available technology - at a time when German television stations were still using magnetic videotape and broadcasting live programmes from physical studios. And the group created a network of supporters and sponsors who helped them to carry out their most ambitious project, Piazza virtuale, in 1992.

The "Hallos" of the callers earned the show the mocking nickname "Hallo TV". This was meant as a pot-shot about the perceived lack of content of the show. Today, the term seems to have taken on a different meaning. If you enter an unfamiliar room full of people that you do not know, you might introduce yourself with a "Hallo". The countless "Hallos" at Piazza virtuale are just that: a first utterance in a new, unfamiliar space, a timid attempt to make contact. Who else is there?

Although the works of Van Gogh TV are among the most important media art projects of the last decades and Piazza virtuale was the largest ever television project by artists, until recently there has been no scholarly literature on the group. Perhaps more importantly, there was hardly any audio-visual documentation of their achievements. Despite their pioneering role, they are either not mentioned at all in the relevant standard works on media and internet $\operatorname{art}^{1}$

1 Decker, Edith; Weibel, Peter (eds.), Vom Verschwinden der Ferne: Telekommunikation und Kunst, Köln: Dumont, 1990; Dinkla, Söke, Pioniere Interaktiver Kunst, Karlsruhe: Cantz, 1997; Frieling, Rudolf; Daniels, Dieter (eds.), Medien Kunst Interaktion: Die 8oer und 9oer]ahre in Deutschland / Media Art Interaction: The 1980 and 1990 in Germany, Vienna: Springer, 2000; Frieling, Rudolf; Daniels, Dieter (eds.), Medien Kunst Netz 1: Medienkunst im Überblick, Vienna: Springer, 2004; Frieling, Rudolf; Daniels, Dieter (eds.): Medien Kunst Netz 2 / Media Art Net 2: Thematische Schwerpunkte / Key Topics, Vienna: Springer, 2005; Frieling, Rudolf; Herzogenrath, Wulf (eds.), 40jahrevideokunst.de: Digitales Erbe: Videokunst in Deutschland von 1963 bis heute, Stuttgart: Hatje Cantz Verlag, 2006; Greene, Rachel, Internet Art: Modern and Contemporary Art (World of Art), London: Thames \& Hudson, 2004, Paul, Christiane, Digital Art, London: Thames \& Hudson, 2002; Frieling, Rudolf; Daniels, Dieter; Herzogenrath, Wulf, 40yearsvideoart.de Digi- 
or only in passing. ${ }^{2}$ The vast majority of texts about the group - more than 150 in the German and international press - appeared in newspapers and in art and cultural magazines before and during Piazza virtuale. When the show ended, there was virtually no concluding reflection, nor was there any longerterm historicisation of the show. And, even worse, there was little opportunity to actually see what was broadcast during the more than three months that Piazza virtuale was on air, apart from some random clips on YouTube that were uploaded by some of the participants or fans of the show.

After a long hiatus, the group started work on its archive in the mid2010s. They used the occasion of an exhibition at a gallery in Berlin to view and put in order the video recordings of the show with the plan to make these records available for research. ${ }^{3}$ From an archival perspective, the amount of material that emerged from this activity was intimidating: more than 800 hours of broadcast recordings, three dozen files of correspondence, a hard disk from a $1992 \mathrm{Mac}$, and some of the technical equipment that had been specially developed by the group.

Van Gogh TV offered the material to the Institut für Mediengestaltung (Institute for Media Design) at Hochschule Mainz, which partnered with the Abteilung für Medienwissenschaft (Department of Media Studies) at Rheinische Friedrichs-Wilhelms-Universität Bonn in order to apply to Deutsche Forschungsgemeinschaft (DFG) for a research grant to work on the estate of Van Gogh TV. Funding was granted from April 2017 to March 2021; the research eventually went on until August of that year.

Van Gogh TV's Piazza virtuale inhabits its own unique space in the prehistory of internet culture, virtual communities and internet art. But unlike later projects of net.art that have been archived or made accessible again in the last couple of years by initiatives such as Rhizome.org, ${ }^{4}$ the legacy of Van Gogh TV is mostly not digital, a factor that turned out to be a blessing in

tal Heritage: Video Art in Germany from 1963 to the Present, Stuttgart: Hatje Cantz Verlag, 2006; Tribe, Mark; Jana, Reena, New Media Art, Cologne: Taschen Verlag, 2006.

2 Daniels, Dieter, Kunst als Sendung: Von der Telegraphie zum Internet, Munich: Verlag C. H. Beck, 2002; Daniels, Dieter; Berg, Stefan, Telegen: Kunst und Fernsehen, Munich: HirmerVerlag, 2015.

3 Baumgärtel, Tilman, "Heute heißt das Chat: Van Gogh TV haben in Zeiten von Bundespost und Rundfunk das Netz gedacht. In Berlin ordnen sie ihren Nachlass", taz. die tageszeitung, 12 September 2014, https://www.taz.de/!297292/

4 Connor, Michael J.; Dean, Aria; Espenschied, Dragan (eds.), The Art Happens Here: Net Art Anthology, New York: Rhizome, 2019. 
disguise. Whereas we first lamented the large volume of material that we had to digitise in order to process it using contemporary methodologies and technologies, we gradually began to understand that we could only access such a rich trove of material because it was mostly analogue. Whatever was digital in the estate of Van Gogh TV had practically become inaccessible in the more than two decades since Piazza virtuale. The VHS and Betamax tapes that were delivered to us in stacks of boxes might not have been as easily handled as a collection of contemporary digital files on a hard disk or in the "cloud" on some server. The recordings on obscure, long-obsolete video formats such as MII, Hi8, U-matic or S-VHS required players that are no longer manufactured and are only available at specialised labs. The three dozen files with photos and paper correspondence with collaborators were not readily searchable for keywords, nor could they easily be filed and analysed using contemporary computer programs. In addition, the many faxes on thermal paper that were found in these files were often faded and hard to read.

However, as cumbersome as the work with this material seemed at first, we eventually understood that the analogue material had survived for a period of time that most digital formats do not. If Pizza Virtuale had taken place only a few years later, most of the correspondence would have been via email and would most likely no longer be accessible. Digital video recordings from the mid-1990s onward were typically saved on data storage media that are now even less accessible than the old analogue tapes.

After three years of research, all the material that we received from Van Gogh TV has been digitised. Videos, letters, photos, slides, sketches, notes and faxes are stored on hard disks and in the "cloud" in formats that we have reason to believe will not be obsolete in a couple of years. We set up a website with clips from the programme and other materials that give an impression of the nature and scope of the show.

There are excerpts from each of the 14 segments that the group developed and from each of the 24 Piazzettas, the micro-studios set up all over Europe that contributed their own programming to Piazza virtuale, transcripts of the more than 30 interviews with Van Gogh TV, contributors to the show and contemporary witnesses we conducted during our research and a sizeable selection of other sources. Much of this information on the website is linked via $\mathrm{QR}$-codes to this book to allow the reader direct access to the multimedia material that cannot be reproduced in a printed publication. We hope that this material will allow the reader to come up with their own answers to the 
principal question that guided our research: How did a group of artists, in 1992, conceive the idea to start their own television station? Was their show a forerunner of the social media of today? And what is their relevance in the history of telecommunication and internet art that began in the 1960s and has become an important genre in contemporary art.

This book will provide a theoretical and historical framework for the development of Piazza virtuale and locate Van Gogh TV in the genealogy of media and media art history. From the perspective of the electronic mass media, the projects of Van Gogh TV and Piazza virtuale in particular occupy a unique place in the historical trajectory of television in the Federal Republic of Germany, in which democracy and participation played an important role from the 1970s onwards. From the perspective of the new online media, Piazza virtuale was a first step into the newly discovered "cyberspace". Seen in the context of contemporary art, there are points of comparison between the activities of the group and the concept of Joseph Beuys' "social sculpture". ${ }^{5}$ As I will show, Piazza virtuale was also an attempt to introduce performance art with audience participation into the mass medium of television. And in the context of media art, their promises of direct involvement of the viewer are realized in a way that goes far beyond the interactive installations common in this art genre at that time.

We will start with a broad overview of the dominant tendencies in the contemporary art of the post-war period that were of relevance to Piazza virtuale. The first chapter will also show how Van Gogh TV addressed in its artistic practice brand-new social, cultural and media developments that unfolded in the 1990 s and still determine our lives today. Perhaps surprisingly, apart from developments in performance and media art, we will also look at the punk and new wave scene out of which the group emerged, and new management techniques that were developed in the context of post-Taylorism that led to the New Economics of the 1990s, as some of the founders and members of Van Gogh TV went on to found their own media companies. Arguably, Van Gogh TV was a forerunner of the start-up culture of the 1990s onwards.

As the group developed out of an artistic culture that put a premium on collective creative action, we will then look at some of the art collectives and projects that the members of the group were involved with before the founding of Van Gogh TV, as well as the umbrella organisation Ponton. Based on

5 See Baumgärtel, Tilman, Eintritt in ein Lebewesen, Berlin: Kunstraum Kreuzberg, 2020. 
research in the files received from the group, we will then reconstruct the process that led in a remarkably short time to the development of Piazza virtuale and the activities and work organisation in Kassel during the period of broadcast. We will look at audience reaction, the press and PR work and the interactions with the sponsors of the show. Finally, in the appendices, there are in-depth descriptions of the various segments (Appendix 1), the contributions of the Piazzettas (Appendix 2) and the technological innovations that the group created (Appendix 3).

Here's hoping that this account of the work of Van Gogh TV will lead to the rediscovery and a reappraisal of Van Gogh TV and of Piazza virtuale. All the necessary material is available now. You only have to look at it. 



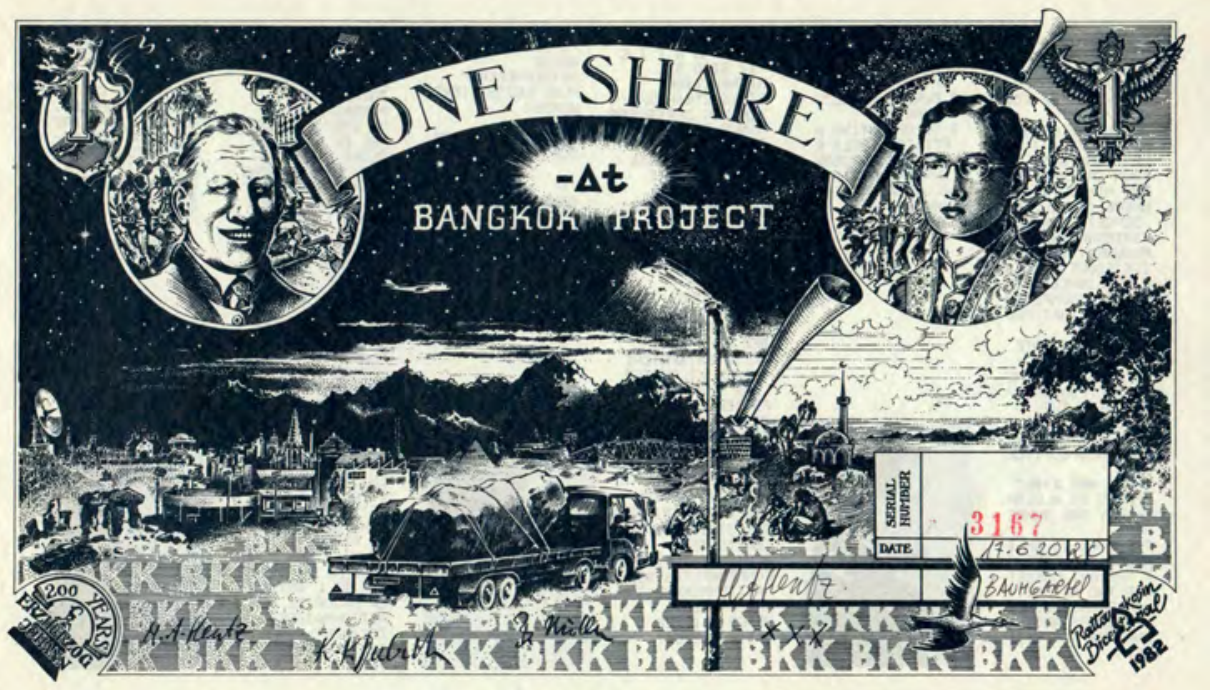

The "art stock" of Minus Deltat (1982) 